\title{
CONSTRUÇÃO DE MODELOS TRIDIMENSIONAIS DE HISTOLOGIA ANIMAL COMO FERRAMENTA FACILITADORA DO APRENDIZADO NO ENSINO MÉDIO
}

Bárbara Prenazzi BRANDÃO푸 Laura Ferreira de Albuquerque BAÊTA²; Ana Paula de Lima Florentino MATTA $^{3}$

\begin{abstract}
1,2Graduanda em Licenciatura em Ciências Biológicas pelo Instituto Federal de Educação, Ciência e Tecnologia do Sudeste de Minas Gerais; ${ }^{3}$ Professora do Instituto Federal de Educação, Ciência e Tecnologia do Sudeste de Minas Gerais - Campus Barbacena, Doutora em Biologia Celular e Estrutural
\end{abstract}

E-mail principal: barbaraprenazzi@hotmail.com

DOI: $10.47094 /$ ICONECBIO.2020/1

Introdução: A histologia compreende o estudo das células e tecidos, e devido as pequenas dimensões das células, o microscópio é uma ferramenta ideal para sua compreensão. Porém, a carência de laboratórios bem estruturados, de microscópios e lâminas permanentes nas escolas, dificultam o processo de ensino e aprendizagem desse conteúdo. Somado a isso, os conteúdos de histologia nos livros didáticos de ensino médio são bem reduzidos e com certa escassez de imagens que contribuam para a compreensão do assunto. Diante das dificuldades citadas, verificou-se a necessidade de desenvolver de um material tridimensional em biscuit e um atlas para complementar as aulas de histologia animal, já que o uso de modelos tridimensionais favorece o aprendizado e transforma a aula em um momento lúdico e prazeroso. Objetivos: Elaborar modelos tridimensionais de Histologia e um atlas digital com fotos das peças construídas. Metodologia: Foi realizada uma seleção de imagens histológicas tridimensionais e posterior confecção dos modelos em biscuit. Os tecidos representados foram: epitelial, conjuntivo (frouxo, sanguíneo, adiposo e ósseo), nervoso e muscular. Por fim, um atlas foi produzido para identificação das estruturas de cada peça. Resultados: Foram confeccionados 11 modelos didáticos tridimensionais de histologia animal, evidenciando as células de cada tecido. As peças foram produzidas em cores aproximadas dos corantes vistos nas lâminas histológicas, e tiveram suas imagens capturadas. Posteriormente, as fotografias foram utilizadas para a confecção do atlas digital. Houve dificuldades para encontrar figuras tridimensionais e artigos científicos do assunto histologia no ensino médio. Conclusão: A partir dos modelos didáticos, espera-se contribuir com a qualidade do ensino de histologia, que a visualização tridimensional possibilite ao aluno uma associação entre forma e função de cada estrutura deixando a teoria menos abstrata e tornando as aulas mais atrativas e estimulantes, dando ao aluno oportunidade de ser o protagonista da construção do seu aprendizado.

Palavras-chave: Biologia. Material didático. Morfologia.

Área Temática: Ensino de Ciências e Biologia. 